\title{
Reminder System Intervention for Increasing Breast Cancer Knowledge and Screening among Underserved Women in a Community Setting
}

\author{
Jay Brown', Saleh M. M. Rahman',** \\ ${ }^{1}$ Angelo State University, San Angelo, Texas, United States \\ ${ }^{2}$ UCF College of Medicine, Orlando, FL, United States
}

Copyright $\odot 2018$ by authors, all rights reserved. Authors agree that this article remains permanently open access under the terms of the Creative Commons Attribution License 4.0 International License

\begin{abstract}
Though incidence rates of female breast cancer has declined since 1975 to 2014 , in women of ages 20-59 years old, breast cancer is the leading cause of cancer-related deaths in the United States. Early detection of breast cancer via screening mammography has been shown to improve options for treatment, outcomes, and survival. Despite the success of screening mammography, screening adherence remains critical for clinical outcomes. This study explored the effect of a reminder system with educational materials on breast cancer knowledge and screening practices among primarily African-American women in North Florida. The participants were divided into two groups: the experimental group, which received this reminder system, and a control group, which did not. Both groups were surveyed using a questionnaire that included nine true or false questions regarding breast cancer facts, statistics, and screening guidelines. The experimental group scored significantly higher $[\mathrm{t}(138)=$ $2.60, \mathrm{p}<.010]$ than the control group regarding breast cancer knowledge. Based on this study, a reminder system can be recommended as an effective intervention for increasing breast cancer knowledge.
\end{abstract}

Keywords Breast Cancer Screening, Reminder System, Cancer Prevention

\section{Introduction}

Breast cancer is the second most common cancer among women in the United States behind non-melanoma skin cancer [1]. It is also the second leading cause of cancer death among women behind lung cancer [1]. According to the Centers of Disease Control and Prevention (CDC) there were 236,968 women in the US diagnosed with breast cancer and 41,211 women dying from the disease in 2014 (the latest year for which data is available) [2,3]. While breast cancer incidence and mortality rates have been decreasing overall, a clear racial disparity still persists $[4,5,6]$. The incidence trends measured by the CDC from 2000 to 2013 show that breast cancer has decreased significantly by $1.12 \%$ per year among white women while it has actually increased significantly by $1.05 \%$ per year among black women during the same time period [7]. In fact, breast cancer is currently the number one most common cancer among black women in the US [1].

The purpose of this study was to increase breast cancer knowledge and screening intention among African-American women in Leon and Gadsden County, Florida by instituting a reminder system known as "A Friends Is She Who Reminds Me" (AFISWRM) $[8,9,10,11]$. By utilizing the construct of "cues to action" within the Health Belief Model coupled with the "behavioral intention" construct within the Integrated Model of Behavior Change, this intervention aimed to not only prompt but also reinforce mammogram screening usage among the women who participate in a complimentary mammography services initiative.

A screening mammogram is an x-ray picture of the breast used to check for tumors and microcalcifications among women with no signs or symptoms of the diseases [7]. The American Cancer Society (ACS) maintains that detecting breast cancer early before there are symptoms such as lumps has been credited for saving thousands of lives every year $[1,12]$. Symptoms of breast cancer usually indicate that the tumor is larger and most likely have already spread beyond the breast tissue. Since black women are more likely to be diagnosed with breast cancer at stage II than stage I, have a larger tumor size, and a higher tumor grade, they are at a much greater risk by the time the cancer is identified [5]. This experiment intended to lower this large health disparity by increasing the breast cancer knowledge of African-American women. Therefore, 
the research question proposed stated: are women who participate in a mammogram reminder program more knowledgeable regarding breast cancer facts, statistics, and screening guidelines than women who do not participate?

Cosp et al. [13] assessed the effectiveness of different strategies used to increase the participation of women in breast cancer screening programs. They discovered that a letter of invitation, a phone call, a letter of invitation plus a phone call, and training activities with direct reminders were all helpful ways on increasing participation rate. However, the most effective method was actually mailed educational materials. Women who were sent educational materials in the mail were almost three times more likely (Odds Ratio 2.81, 95\% Confidence Interval 1.96 to 4.02 ) to participate in the community program than women with no intervention. Therefore, this intervention method was utilized by this study since it has been shown to be the most useful strategy for higher participation.

Krueter et. al (1999) [14] contended that mass produced brochures, booklets, and pamphlets are not ideal for reaching specific communities. They believed printed materials educational materials should fit the unique interests, needs, and concerns of the individuals being targeted. This study followed their guidelines by obtaining information from reputable national cancer organizations and specifying the message to the target population. Information of particular concern to African-Americans were utilized in the creation of the educational packet in order to directly reach this community.

This study utilized both the Health Belief Model and the Integrated Model of Behavior in its framework. The gaining of new information was considered a "cue to action" as it was the trigger that prompted engagement in health-promoting behaviors [15]. Also, any increased awareness of a health-promoting behavior may serve as motivation for an individual to further increase their knowledge of it. This increased knowledge then leads to greater behavioral intention by increasing an individual's awareness of the illness/disease [16]. Knowledge can affect other constructs of the Health Belief Model such as perceived susceptibility by letting certain populations know they may be at greater risk for an illness/disease or perceived benefits by making them aware of the positive results that can be achieved through preventative action. Finally, behavioral intention is shown leading to behavior since the Integrated Model of Behavior and its predecessors consider intention to be the direct antecedent to actual behavior change.

For personal preference, you may import styles into your own manuscript. The process is divided into 4 steps:

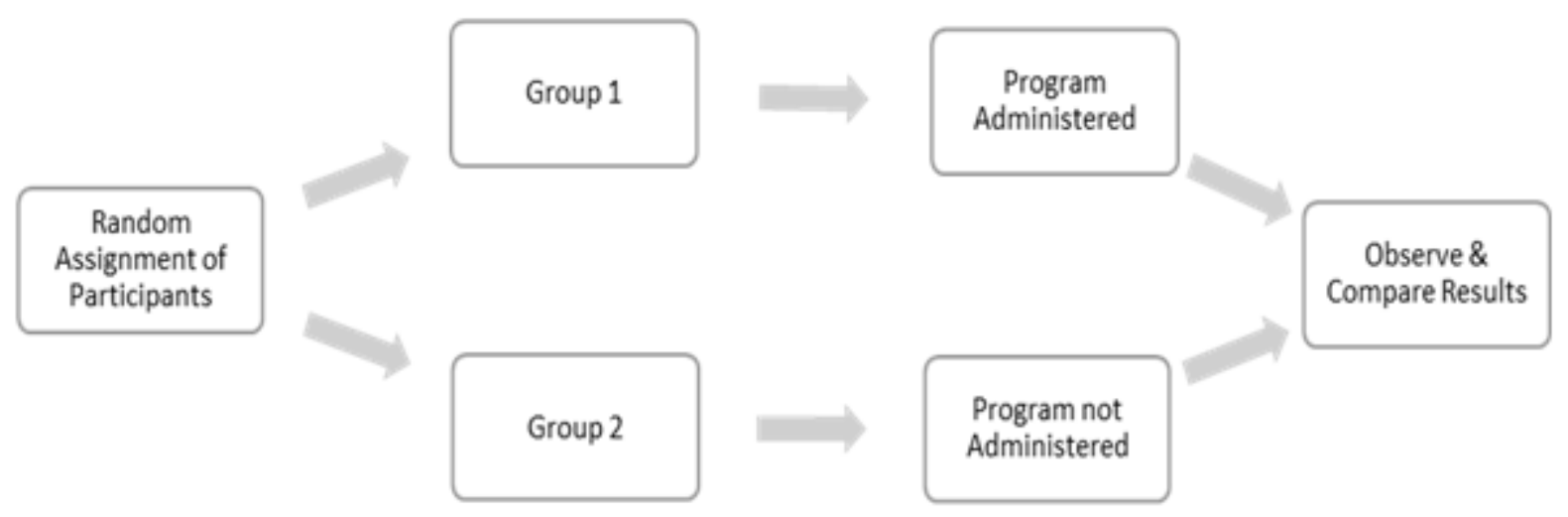

Figure 1. wo-group post-test experimental design 


\section{Materials and Methods}

The Health Belief Model postulates that a trigger is necessary to initiate health-promoting behaviors. These cues can be internal such as pain or symptoms from a disease or they can be external such as events that occur or the reception of information from media, health care providers, or close friends. This reminder system employed the external cue of information reception through the dissemination of comprehensive packets to participating women as a trigger for mammography screening utilization. This system was labeled "A Friend Is She Who Reminds Me" (AFISWRM).

Community Outreach and Preventive Services (COPS) Core of a P20 Center of Excellence for Cancer Research, Training and Services offered complimentary mammograms to women age 40 and older (or African American women over the age of 35) residing in Leon or Gadsden County who are uninsured or underinsured. COPS implemented a CBPR-Social Marketing Intersection Model $[17,18]$. A survey was conducted on each of these women prior to the screening in order to determine their perceptions regarding mammogram screenings. The Health Belief Model was utilized in the creation of the survey in order to measure their perceived susceptibility, severity, barriers, and benefits of utilizing these preventive services. This reminder system utilized the missing integral construct of cues to action and measured its effect on this population.

AFISWRM contained various components regarding breast cancer information and screening. Each packet included an educational brochure (see appendix I) outlining the basic facts and statistics about breast cancer and the benefits of early detection. This brochure included information on who is at risk of developing breast cancer and what exactly are mammogram screenings. It was considered to be the major resource for increasing breast cancer knowledge among the experimental group.

This reminder system also included a comprehensive resource list (see appendix II) for participants who were looking for more information or patients who have unfortunately received a negative or uncertain diagnosis. This collection contained the telephone numbers, websites, and physical addresses (if available) of breast cancer resources at the local, regional, national, and even international levels. These organizations, foundations, and institutions could further assist women in need after mammogram screening services are completed. They comprised of Reach to Recovery, Bosom Buddies, Sisters Alive, Florida Breast Cancer Foundation, Susan G. Komen for the Cure, and dozens of others.

The final piece of the packet was a small handout (see appendix III) with clear concise instructions on how to participate in this reminder system. It contained a numbered list with five blank lines and checkboxes next to each one. Participants were asked to fill in the names of five friends who may also be interested in a free clinical breast exam. Once they have contacted each friend and informed them of the program, they simply checked off the checkbox next to their name on the card. If each participant followed through, then it was theoretically possible for fifty (50) women to encourage two hundred and fifty (250) more to set up an appointment for mammogram screening.

This study utilized the two-group posttest-only randomized experimental design. This design begins by randomly dividing participants into two groups: experimental and control. The experimental group receives the treatment or program while the control group does not.

A pretest is usually included to determine whether the two groups are comparable prior to the program. However, a pretest is unnecessary for this design since random assignment allows probabilistic equivalence among the groups. The superordinate goal of this design lies in determining whether the two groups are different after the program. The observational measures will be taken via the telephone survey as their responses and compared by testing for the differences between the two groups.

The two-group posttest-only randomized experiment is strong against all the single-group threats to internal validity such as history, maturation, instrumentation, testing, and mortality since it has two groups. It is also effective against all the multiple-groups threats to internal validity except selection mortality. Differential rates of dropout between the two groups can skew the data in one direction. This design is also susceptible to all the social interaction threats to internal validity due to unknown communication between the members of both groups. However, it is strong against both selection instrumentation and selection testing since the measurements are only taken once. The two-group posttest-only randomized experimental design is considered one of the best research strategies for assessing cause-effect relationships.

All participants were surveyed using a questionnaire (see appendix IV) developed for this study utilizing tested questions from previous breast cancer research. The latest guidelines for survey researchers and Institutional Review Boards (IRBs) published by the American Association for Public Opinion Research (AAPOR) were strictly followed. The AAPOR's guidelines are based on extensive experience with surveys and remains consistent with the recommendations of the National Research Council. Human subject protection is at the forefront of surveys and it continues to be an ever-evolving topic (AAPOR, 2014). This study was approved by the Institutional Review Board at Florida Agricultural \& Mechanical University.

Knowledge of any particular health concern can greatly impact one's behavior regarding that area. Therefore, the survey consisted of nine (9) true or false questions concerning breast cancer information, statistics, and screening guidelines from previously published breast cancer studies (Rahman et. al., 2014). These questions included: 
- Q10: Breast cancer is the most common cancer among African American women.

- Q11: Breast cancer is the leading cause of cancer death among all women.

- Q12: Women with a mother or sister with breast cancer are more likely to develop breast cancer than women without a family history.

- Q13: Women who has already had breast cancer are more likely to develop breast cancer again.

- Q14: Yearly mammogram screenings for breast cancer is recommended for all women starting at age 40 .

- Q15: Women ages 20-39 should have a Clinical Breast Exam (CBE) every 3 years.

- Q16: Race, income, education, and access to screening has NO effect on a woman's breast cancer risk.

- Q17: If detected early, a woman's chance of surviving breast cancer is good.

- Q18: One out of every eight women in the United States will get breast cancer during their lifetime.

This population sample was randomly divided into two (2) groups determined by the result of a coin flip. A result of "heads" categorized participants into the experimental group and a result of "tails" categorized them into the control group. The experimental group participated in the reminder system AFISWRM and the control group was not a part of this program. All participants were called and asked for verbal consent to participate. The control group was administered the questionnaire via telephone survey immediately, but the experimental group was called back for survey completion upon reception of the intervention $[19,20]$. There were 101 participants within the control group and 38 participants in the experimental group for a total population of 139 in this study. Their responses were kept confidential and locked away in a file cabinet in the principal investigator's office on campus. Upon completion, the questionnaires were entered into a password-protected database and Statistical Package for the Social Sciences (SPSS) was used for data analysis.

\section{Results}

Table 1 shows the demographical data of the entire study population. The majority of participants self-described as black or African-American (79.29\%) as expected, but there were also $23(16.43 \%)$ participants self-described as white which could allow for future comparisons along the sociopolitical construct of race. The average age of participant was 50 years $(M=49.94, S D=11)$, which was well within the target range. However, the youngest participant was only 28 and the eldest was 83 years of age creating a larger variance than originally expected.

The majority of participants were employed $(56.43 \%)$ at least part-time, but an almost identical amount was either unemployed $(22.14 \%)$ or not working due to retirement of disability $(21.43 \%)$. This high rate of unemployment elucidates the necessity of community-based participatory research. Lack of employment drastically hinders an individual's ability to afford health insurance coverage and thereby limiting their access to essential prevention services. While $43.57 \%$ of all participants had private insurance, almost 20\% were on Medicare and another 30\% had no insurance at all. Without a national option for health insurance, most this population is left without possibly life-saving screening opportunities.

Participant educational level was much more evenly distributed among these three new categories with approximately one-third of the population belonging in each. Total household income was originally measured by increments of $\$ 5,000$ but were later grouped by level of socioeconomic status (SES.) Households earning less than $\$ 20,000$ per year were placed within "Low SES," those in the $\$ 20,000$ to $\$ 39,999$ range were considered "Median SES," and \$40,000 a year or higher were "High SES." The largest group within this study was Low SES with $35.71 \%$ of all participants earning less than $\$ 20,000$ a year. $21.43 \%$ of participants were labeled Median SES with 25.14\% considered High SES, while another $15.71 \%$ preferred not to answer.

Finally, zip codes were collected for geographical representation of study participants. County of residence was then extrapolated using the zip codes given. Most participants resided in Leon County (69.29\%) followed by Gadsden County (27.86\%), while there were only a few in Broward (1.43\%), Jackson (0.71\%), and Madison (0.71\%).

The knowledge portion of the survey consisted of nine true or false questions regarding breast cancer facts, statistics, and screening guidelines. The participants were capable of answering the majority of questions correctly except for Q11 (breast cancer is the leading cause of death amongst all women) and Q16 (race, income, education, and access to screening has no effect on a woman's risk of breast cancer). These two knowledge questions seemed to be the most difficult due to some common misconceptions about breast cancer. Many people mistakenly believe breast cancer to be the number one cause of cancer death amongst women even though lung cancer has a higher mortality rate. Also, informing the public that race, income, education, and access to screening not only affects breast cancer risk but are the basis behind many other health disparities is an explicit goal of our national health initiative Healthy People 2020.

For the purposes of this study, a cumulative knowledge score was calculated for each participant per their results on the knowledge portion of the questionnaire. The participants were asked nine true or false questions regarding breast cancer facts, statistics, and screening guidelines and SPSS was utilized to assign points based on their responses. One point was given for every correct answer and zero points for every incorrect answer or 
response of "no idea." Breast cancer knowledge was then calculated and scored on a scale of zero (none correct) to nine (all correct).

The average score was approximately $6(\mathrm{M}=5.76, \mathrm{SD}=$ 1.89) out of a possible 9 , suggesting that participants were fairly knowledgeable in regards to breast cancer. Figure 2 shows the frequency of all participant knowledge scores. The bell curve is considered the most common type of distribution for a variable; therefore, knowledge can be regarded as a normal distribution skewed to the right.

The experimental and control groups were compared primarily through cross-tabulations with the Pearson's chi-square test. This test is the most appropriate for this comparison since the Pearson's chi-square test is used to discover if there a relationship exists between two categorical variables.

Table 2 shows the response rates of the experimental and control groups for the knowledge portion of the questionnaire. The experimental group performed better than the control group on every question in the knowledge portion of the survey except for Q16 (race, income, education, and access to screening have no effect on a woman's risk of breast cancer) which they were more likely to give a response of both "true" and "false." However, the experimental group was found statistically significantly, $\chi 2(2, \mathrm{~N}=139)=6.34, \mathrm{p}=.042$, less likely to answer "no idea" to this question than the control group. The experimental group was also less likely to answer "no idea" to every question than the control group with the exception of Q13 (women who have already had breast cancer in one breast are more likely to develop breast cancer in the other breast). Finally, a statistically significant difference was found using Pearson Chi-Square for Q18 (one out of every eight women in the United States will get breast cancer during their lifetime) $\chi 2(2, \mathrm{~N}=139)$ $=6.00, p=.050$, showing that the experimental group was more likely to answer this question correctly than the control group.

Table 3 shows the results of an independent samples t-test for equality of means comparing the average knowledge scores of the study groups. This statistical test was the best fit for this analysis as it determines whether there is a statistically significant difference between the means of two unrelated groups. The experimental and control groups were the independent categorical variable and the knowledge score was the continuous dependent variable. The overall knowledge score of the groups were calculated on a scale of 0 (none correct) to 9 (all correct) and the average score for the control group was found to be $5.5(\mathrm{SD}=1.87)$ compared to an average score of $6.4(\mathrm{SD}=$ 1.79) for the experimental group. This difference was found to be statistically significant according to a t-test, $t(138)=2.60, p<.010$. Therefore, the null hypothesis stating that the two population means are equal can be rejected. The experimental group had a statistically higher average knowledge score than the control group.

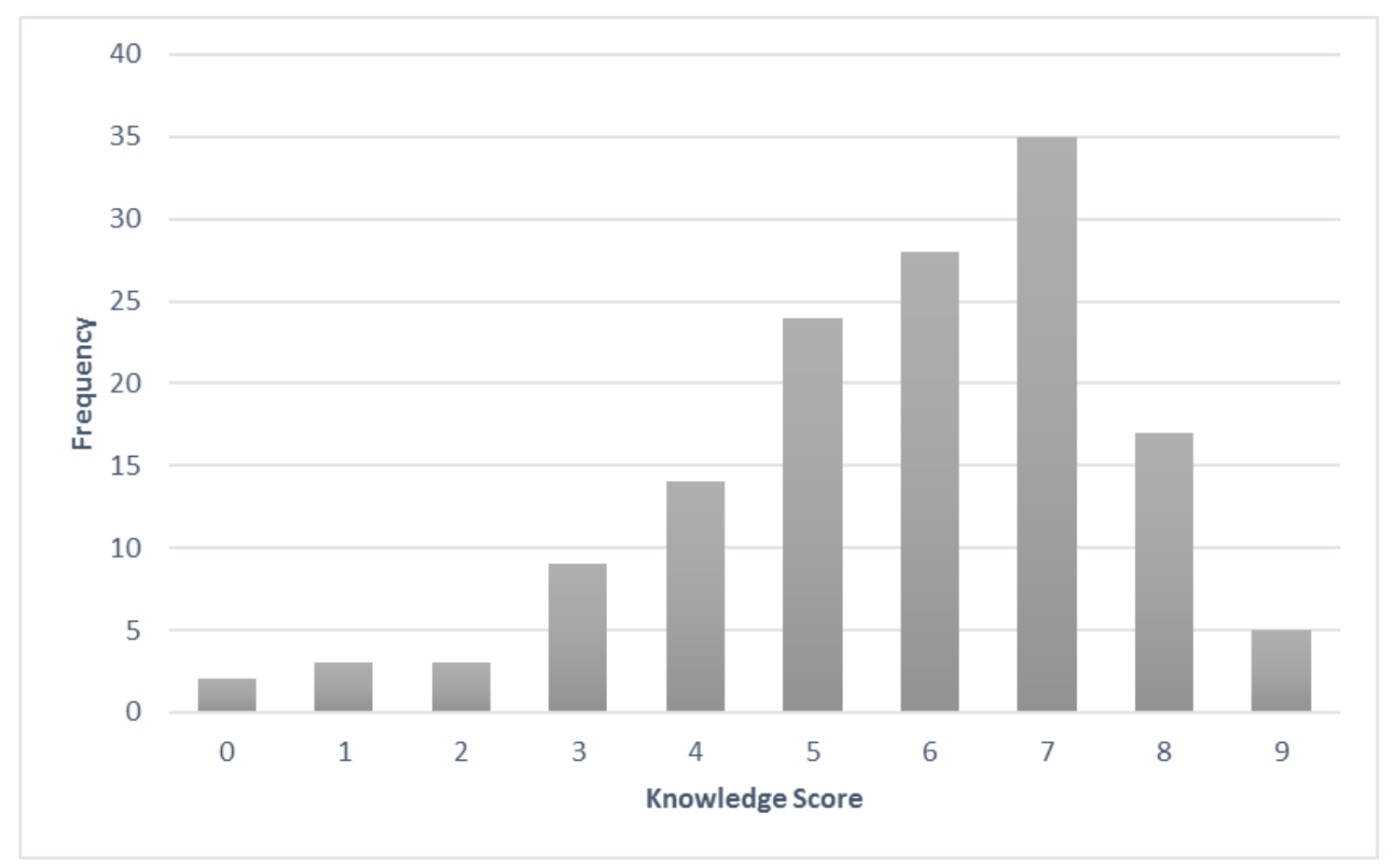

Figure 2. Chart of overall participant knowledge scores 
Table 1. Demographical data of all participants

\begin{tabular}{|c|c|c|c|}
\hline Variables & n (\%) & Variables & n (\%) \\
\hline Age & & Relationship Status & \\
\hline Mean (SD) & $49.94(11)$ & Married & $38(27.14 \%)$ \\
\hline Race/Ethnicity & & Widowed & $7(5.00 \%)$ \\
\hline Black/African-American & $111(79.29 \%)$ & Divorced & $17 \quad(12.14 \%$ \\
\hline White & $23(16.43 \%)$ & Separated & $1(0.71 \%)$ \\
\hline $\begin{array}{c}\text { Asian } \\
\text { Hispanic/Latina } \\
\text { Multiple races }\end{array}$ & $\begin{array}{c}2(1.43 \%) \\
3(2.14 \%) \\
1(0.71)\end{array}$ & $\begin{array}{c}\text { Single } \\
\text { Educational Level } \\
\text { No college (high school } \\
\text { diploma/GED or less) }\end{array}$ & $49(35.00 \%)$ \\
\hline Employment Status & & $\begin{array}{l}\text { Some college (including } \\
\text { Associate degree) }\end{array}$ & $46(32.86 \%)$ \\
\hline Employed, working full-time & $65(46.43 \%)$ & College (or graduate) degree & $45(32.14 \%)$ \\
\hline Employed, working part-time & $14(10.00 \%)$ & Household income & \\
\hline Unemployed, but looking & $23(16.43 \%)$ & Low SES (less than $\$ 20,000$ ) & $50(35.71 \%)$ \\
\hline Unemployed, not looking & $8(5.71 \%)$ & Median SES $(\$ 20,000-39,999)$ & $30(21.43 \%)$ \\
\hline $\begin{array}{c}\text { Retired } \\
\text { Unable to work } \\
\text { Insurance Status }\end{array}$ & $\begin{array}{c}22(15.71 \%) \\
8(5.71 \%)\end{array}$ & $\begin{array}{c}\text { High SES (\$40,000 or higher) } \\
\text { Prefer not to answer } \\
\text { County }\end{array}$ & $\begin{array}{l}38(27.14 \%) \\
22(15.71 \%)\end{array}$ \\
\hline Private Insurance & $61(43.57 \%)$ & Leon & $97(69.29 \%)$ \\
\hline Medicare/Medicaid & $27(19.29 \%)$ & Gadsden & $39(27.86 \%)$ \\
\hline Affordable Care Act & $6(4.29 \%)$ & Jackson & $2(1.43 \%)$ \\
\hline Uninsured & $41(29.29 \%)$ & Madison & $1(0.71 \%)$ \\
\hline Other & $4(2.86 \%)$ & Broward & $1(0.71 \%)$ \\
\hline
\end{tabular}

Table 2. Group comparison of responses to knowledge questions

\begin{tabular}{|c|c|c|c|c|c|c|}
\hline \multirow[t]{2}{*}{ Survey Item } & \multicolumn{2}{|c|}{ True } & \multicolumn{2}{|c|}{ False } & \multicolumn{2}{|c|}{ No Idea } \\
\hline & Experimental & Control & Experimental & Control & Experimental & Control \\
\hline $\begin{array}{l}\text { Q10: Breast cancer is the most common } \\
\text { cancer among African American women. }\end{array}$ & $\begin{array}{c}31 * \\
(79.49 \%)\end{array}$ & $\begin{array}{c}62 * \\
(61.39 \%)\end{array}$ & $\begin{array}{c}3 \\
(7.69 \%)\end{array}$ & $\begin{array}{c}21 \\
(20.79 \%)\end{array}$ & $\begin{array}{c}5 \\
(12.82 \%)\end{array}$ & $\begin{array}{c}18 \\
(17.82 \%)\end{array}$ \\
\hline $\begin{array}{l}\text { Q11: Breast cancer is the leading cause of } \\
\text { cancer death among all women. }\end{array}$ & $\begin{array}{c}18 \\
(47.37 \%)\end{array}$ & $\begin{array}{c}54 \\
(53.47 \%)\end{array}$ & $\begin{array}{c}14 * \\
(36.84 \%)\end{array}$ & $\begin{array}{c}24 * \\
(23.76 \%)\end{array}$ & $\begin{array}{c}6 \\
(15.79 \%)\end{array}$ & $\begin{array}{c}23 \\
(22.77 \%)\end{array}$ \\
\hline $\begin{array}{l}\text { Q12: Women with a mother or sister with } \\
\text { breast cancer are more likely to develop } \\
\text { breast cancer than a woman without a } \\
\text { family history. }\end{array}$ & $\begin{array}{c}31 * \\
(81.58 \%)\end{array}$ & $\begin{array}{c}74 * \\
(73.27 \%)\end{array}$ & $\begin{array}{c}6 \\
(15.79 \%)\end{array}$ & $\begin{array}{c}14 \\
(13.86 \%)\end{array}$ & $\begin{array}{c}1 \\
(2.63 \%)\end{array}$ & $\begin{array}{c}13 \\
(12.87 \%)\end{array}$ \\
\hline $\begin{array}{l}\text { Q13: Women who have already had } \\
\text { breast cancer in one breast are more likely } \\
\text { to develop breast cancer in the other breast. }\end{array}$ & $\begin{array}{c}28^{*} \\
(73.68 \%)\end{array}$ & $\begin{array}{c}65^{*} \\
(64.36 \%)\end{array}$ & $\begin{array}{c}3 \\
(7.89 \%)\end{array}$ & $\begin{array}{c}19 \\
(18.81 \%)\end{array}$ & $\begin{array}{c}7 \\
(18.42 \%)\end{array}$ & $\begin{array}{c}17 \\
(16.83 \%)\end{array}$ \\
\hline $\begin{array}{l}\text { Q14: A yearly mammogram screening for } \\
\text { breast cancer is recommended for all } \\
\text { women starting at } 40 \text {. }\end{array}$ & $\begin{array}{c}35^{*} \\
(92.11 \%)\end{array}$ & $\begin{array}{c}81 * \\
(80.20 \%)\end{array}$ & $\begin{array}{c}3 \\
(7.89 \%)\end{array}$ & $\begin{array}{c}14 \\
(13.86 \%)\end{array}$ & $\begin{array}{c}0 \\
(0.00 \%)\end{array}$ & $\begin{array}{c}6 \\
(5.94 \%)\end{array}$ \\
\hline $\begin{array}{l}\text { Q15: Women ages } 20-39 \text { should have a } \\
\text { clinical breast exam every } 3 \text { years. }\end{array}$ & $\begin{array}{c}28^{*} \\
(73.68 \%)\end{array}$ & $\begin{array}{c}61^{*} \\
(60.40 \%)\end{array}$ & $\begin{array}{c}6 \\
(15.79 \%)\end{array}$ & $\begin{array}{c}21 \\
(20.79 \%)\end{array}$ & $\begin{array}{c}4 \\
(10.53 \%)\end{array}$ & $\begin{array}{c}19 \\
(18.81 \%)\end{array}$ \\
\hline $\begin{array}{l}\text { Q16: Race, income, education, \& access to } \\
\text { screening have no effect on a woman's risk } \\
\text { for breast cancer. }\end{array}$ & $\begin{array}{c}23 \\
(60.53 \%)\end{array}$ & $\begin{array}{c}51 \\
(50.50 \%)\end{array}$ & $\begin{array}{c}15 * \\
(39.47 \%)\end{array}$ & $\begin{array}{c}35 * \\
(34.65 \%)\end{array}$ & $\begin{array}{c}0 \\
(0.00 \%)\end{array}$ & $\begin{array}{c}15 \\
(14.85 \%)\end{array}$ \\
\hline $\begin{array}{l}\text { Q17: If detected early, a woman's chance } \\
\text { of surviving breast cancer is good. }\end{array}$ & $\begin{array}{c}38^{*} \\
(100 \%)\end{array}$ & $\begin{array}{c}97 * \\
(96.04 \%)\end{array}$ & $\begin{array}{c}0 \\
(0.00 \%)\end{array}$ & $\begin{array}{c}2 \\
(1.98 \%)\end{array}$ & $\begin{array}{c}0 \\
(0.00 \%)\end{array}$ & $\begin{array}{c}2 \\
(1.98 \%)\end{array}$ \\
\hline $\begin{array}{l}\text { Q18: One out of every } 8 \text { women will get } \\
\text { breast cancer during their lifetime. }\end{array}$ & $\begin{array}{c}30 * \\
(78.95 \%)\end{array}$ & $\begin{array}{c}57 * \\
(56.44 \%)\end{array}$ & $\begin{array}{c}3 \\
(7.89 \%)\end{array}$ & $\begin{array}{c}18 \\
(17.82 \%)\end{array}$ & $\begin{array}{c}5 \\
(13.16 \%)\end{array}$ & $\begin{array}{c}26 \\
(25.74 \%) \\
\end{array}$ \\
\hline
\end{tabular}

*Denotes correct answer

Table 3. Group knowledge score t-test

\begin{tabular}{ccccc}
\hline Group & Knowledge Score & \multicolumn{3}{c}{ t-test for Equality of Means } \\
\hline & Mean (SD) & df & t & Sig. \\
Experimental & $6.41(1.79)$ & 138 & 2.595 & $0.010^{*}$ \\
Control & $5.51(1.87)$ & & & \\
\hline
\end{tabular}

*Denotes statistical significance 


\section{Conclusions}

Based on this study, a recommendation can be made to utilize a reminder system as an intervention for breast cancer screening. AFISWRM included paper educational materials regarding breast cancer facts, statistics, guidelines, and resources that has been shown to effectively increase breast cancer knowledge among study participants. Community programs aimed at improving mammography utilization can be well served by this methodology. By keeping the target population informed and engaged, the health disparities observed between the races can be reduced and ideally eliminated in the future.

\section{Acknowledgements}

We are very grateful to the P20 Center of Excellence for Cancer Research, Training and Community Services. Particularly the Community Outreach and Preventive Services Core (Funding NIH Grant no. 1P20MD006738-01) and the participants from the Leon and Gadsden Counties, FL.

\section{REFERENCES}

[1] American Association for Public Opinion Research. AAPOR guidance for IRBs and Survey Researchers, Online available from:

http://www.aapor.org/AAPORKentico/Standards-Ethics/In stitutional-Review-Boards/Full-AAPOR-IRB-Statement.as px

[2] American Cancer Society. Breast cancer facts and figures, Online available from:

http://www.cancer.org/acs/groups/content/@research/docu ments/document/acspc-042725.pdf

[3] Andersson, K. Aspegren, L. Janzon, T. Landberg, K. Lindholm, F. Linell, O. Ljungberg, J. Ranstam, B. Sigfusson. Mammographic screening and mortality from breast cancer: the malmo mammographic screening trial. British Medical Journal, Vol. 297, No. 6654, pp. 943-948, 1988.

[4] D. Ansell, P. Grabler, S. Whitman, C. Ferrans, J. B. Bishop, L. R. Murray, R. Rao, E. Marcus. A community effort to reduce the black/white breast cancer mortality disparity in Chicago. Cancer Causes \& Control, Vol. 20, No. 9, pp. 1681-1688, 2009.

[5] D. Ansell, L. Lacey, S. Whitman, E. Chen, C. Phillip. A nurse-delivered intervention to reduce barriers to breast and cervical cancer screening in Chicago inner city clinics. Public Health Reports (1974-), Vol. 109, No. 1, pp. 104-111, 1994.

[6] J. P. B. Berz, K. Johnston, B. Backus, G. Doros, A. J. Rose, S. Pierre, T. A. Battaglia. The influence of black race on treatment and mortality for early-stage breast cancer. Medical Care, Vol. 47, No. 9, pp. 986-992, 2009.
[7] Centers for Disease Control and Prevention. Breast cancer statistics. Division of Cancer Prevention and Control, National Center for Chronic Disease, Online available from: http://www.cdc.gov/cancer/breast/statistics/index.htm

[8] Centers for Disease Control and Prevention/National Center for Health Statistics. National Health Interview Survey, Online available from:

http://www.cdc.gov/nchs/data/nhis/earlyrelease/wireless20 1407.pdf

[9] X. B. Cosp, M. M. Castillejo, M. P. Vila, J. Marti, J. I. Emparanza. Strategies for increasing the participation of women in community breast cancer screening. Cochrane Database of Systematic Reviews 2001, Issue 1. Art. No.: CD002943. doi: 10.1002/14651858.CD002943, 2001.

[10] R. M. Groves, P. P. Biemer, L. E. Lyberg, J. T. Massey, W. L. Nicholls II, J. Waksberg. Telephone survey methodology. Hoboken, New Jersey: Wiley-Interscience, 1998.

[11] M. W. Kreuter, V. J. Strecher, B. Glassman. One size does not fit all: the case for tailoring print materials. Annals of Behavioral Medicine, Vol. 21, No. 276. doi:10.1007/BF02895958, 1999.

[12] P. Lavrakas, C. Shuttles, C. Steeh, H. Fienberg. The state of surveying cell phone numbers in the United States: 2007 and beyond. Public Opinion Quarterly, Vol. 71, No. 5, pp. 840-854, 2007.

[13] L. K. Meillier, A. B. Lund, G. Kok. Cues to action in the process of changing lifestyle. Patient Education Counseling, Vol. 30, No. 1, pp. 37-51, 1997.

[14] S. M. M. Rahman, A. Battle, C. M. Harris, M. Mitchell, K. A. Soliman. Building community-academic partnership to conduct Community Based Participatory Research (CBPR) to reduce breast cancer disparities: lessons from a P20 COE Project. International Symposium on Minority Health and Health Disparities. December 1-3, MD, 2014.

[15] S. Rahman, J. Brown, S. Rahman, H. Vilme, M. Hayes. Evaluation of community-based projects to reduce cancer disparities among underrepresented groups and participants' satisfaction in health disparities projects. Cancer and Oncology Research, Vol. 1, No. 2, pp. 55-64, 2013.

[16] S. M. M. Rahman, M. B. Dignan, B. J. Shelton. A theory-based prediction model for adherence to guidelines for screening mammography among women age 40 and older. International Journal of Cancer Prevention, Vol.2 (3): 169-79, 2005.

[17] S. M. M. Rahman, I. Mohamed, M. B. Dignan. Assessment of Perceptions Related to Breast Cancer Prevention and Behavioral Practices in Medically Underserved Women. The Journal of Multicultural Nursing and Health, Vol.9, No.3:30-39, 2003.

[18] S M. M. Rahman, Arrie Battle, Harris CM., Mitchell M., Soliman KA Building community-academic partnership to conduct Community Based Participatory Research (CBPR) to reduce breast cancer disparities: lessons from a P20 COE Project. International Symposium on Minority Health and Health Disparities. December 1-3, MD, 2014.

[19] R. S. Rao, B. I. Graubard, N. Breen, J. L. Gastwirth. Understanding the factors underlying disparities in cancer screening rates using the Peters-Belson approach: results 
from the 1998 National Health Interview Survey. Medical Care, Vol. 42, No. 8, pp. 789-800, 2004.

[20] S. A. Sabatino, R. J. Coates, R. J. Uhler, N. Breen, F. Tangka, K. M. Shaw, K. M. Disparities in mammography use among US women aged 40-64 years, by race, ethnicity, income, and health insurance status, 1993 and 2005. Medical Care, Vol. 46, No. 7, pp. 692-700, 2008.

[21] S. R. Sturgeon, C. Schairer, D. Grauman, L. E. Ghormli, S. Devesa. Trends in breast cancer mortality rates by region of the United States, 1950-1999. Cancer Causes \& Control, Vol. 15, No. 10, pp. 987-995, 2004.
[22] F. K. L. Tangka, J. Dalaker, S. K. Chattopadhyay, J. G. Gardner, J. Royalty, I. J. E., Hall, A. DeGroff, D. K. Blackman, R. J. Coates. Meeting the mammography screening needs of underserved women: the performance of the National Breast and Cervical Cancer Early Detection Program in 2002-2003 (United States). Cancer Causes \& Control, Vol. 17, No. 9, pp. 1145-1154, 2006.

[23] U.S. Cancer Statistics Working Group. United States Cancer Statistics: 1999-2014 Incidence and Mortality Web-based Report. Atlanta (GA): Department of Health and Human Services, Centers for Disease Control and Prevention, and National Cancer Institute, Online available from: http://www.cdc.gov/us 